\title{
LINGUAGEM E INTERPRETAÇÃO: O RECURSO À LINGUAGEM MENTAL EM OCKHAM ${ }^{*}$
}

Ernesto Perini Santos**

SÍNTESE - Na semântica de Guilherme de Ockham é de fundamental importância o recurso à linguagem mental. Examina-se no presente texto o recurso à linguagem mental para mostrar o modo como ela chega a sentenças compostas que significam sem qualquer comprometimento quanto à realidade psíquica dos atos a que chega.

PALAVRAS-CHAVE - Filosofia Medieval. GuiIherme de Ockham. Linguagem mental. Interpretação. Realidade psíquica.
ABSTRACT - According to William Ockham's semantics it is crucial to resort to mental language. In this article, having recourse to mental language is examined so as to show one arrives at composed sentences which signify without any commitment to the psychic reality of the attained acts.

KEY WORDS - Medieval philosophy. Ockham. Mental language. Interpretation. Psychic reality.

O recurso à linguagem mental (LM) é fundamental na semântica ockhamiana. Discernir traços significativos da linguagem falada (e da linguagem escrita) equivale a associá-los a traços da LM. O critério para identificação de traços pertencentes à LM - o que é relevante para a verdade de sentenças - não é diferente da definição do que é significativo numa linguagem qualquer. É preciso distinguir dois tipos de papel que este recurso à LM pode desempenhar.

(i) A LM é uma realidade psíquica, cada homem de fato pensa pela LM, falar e compreender 0 que outros falam são atividades que, para Ockham, correspondem à associação de sinais sonoros a representações mentais realmente existentes em cada um. Uma teoria acerca da LM é também uma teoria sobre a mente humana, sobre algo realmente existente nos indivíduos. Assim é possível, por exemplo, associar termos mentais a atos de intelecção (Exp. I, 6), ou descrever a gênese de termos mentais recorrendo à teoria do conhecimento (Cf. Panaccio, 1992).

* Agradeço a Celina F. Lage pela ajuda com o latim.

** Departamento de Filosofia, Universidade Federal de Minas Gerais - UFMG.

\begin{tabular}{|l|l|l|l|l|l|}
\hline VERITAS & Porto Alegre & v. 45 & n. 3 & Setembro 2000 & p. $339-348$ \\
\hline
\end{tabular}


(ii) Outro tipo de recurso é o discernimento de traços significativos da linguagem falada e sua associação à LM. Aqui, toda a análise é feita dentro da linguagem falada e por critérios que são operatórios no nível desta análise lingüística, sem recurso a nenhum outro tipo de explicação. Não há comprometimento algum com teses acerca do conhecimento e a única coisa que se requer aqui é a intuição de falantes de alguma língua capazes, por exemplo, de reconhecer diferenças de significado entre diferentes sentenças. Neste caso, a realidade psiquica da LM não é importante; podemos aplicar exatamente o mesmo tipo de análise, i.e. um traço de uma linguagem dada é significativo se e somente se for relevante para a determinação do valor verdade de sentenças, chegar a resultados semelhantes, permanecendo neutros quanto à realidade psíquica da linguagem.

A independência entre estes dois papéis não divide a semântica ockhamiana em dois campos independentes. É necessário ter em mente esta distinção justamente para poder ver onde e como estes dois tipos de recursos aparecem em Ockham e a que tipo de conseqüência cada tese e cada argumento leva a respeito da LM.

Tratarei aqui de um caso do segundo tipo de recurso. Procurarei mostrar como Ockham analisa o modo como sentenças compostas significam sem qualquer comprometimento quanto à realidade psíquica dos resultados a que chega. Mesmo se o Venerabilis Inceptor parte da pergunta pelo modo como proposições são compostas de atos intelectivos, o resultado de sua análise abandona a determinação de realidades psicológicas. Acredito que este tipo de estratégia ockhamiana pode ser vista como interpretativa; trata-se de interpretar um trecho da linguagem, não de explicitar sua realização psicológica.

O início da Expositio in Librum Perihermeneias Aristotelis é um exame da natureza do conceito mental e das relações entre linguagens mental, falada e escrita. A origem desta doutrina das três linguagens é justamente o primeiro livro do $D e$ Interpretatione. Ockham pergunta-se no parágrafo 3 o que é passio animae sive conceptus. Os parágrafos 4, 5 e 7 apresentam soluções recusadas pelo Venerabilis Inceptor. A opinião aceita é a exposta no parágrafo 6, a paixão da alma é o próprio ato de intelecção - passio animae est ipse actus intelligendi - e existe realmente na alma como qualidade (subiective et realiter in anima tamquam veras qualitates ipsius), é uma qualidade individual na alma, formada a partir da apreensão de uma coisa singular. Esta posição deve enfrentar alguns problemas. O primeiro deles é à que corresponde à intelecção de um termo comum. ${ }^{1}$ O segundo problema, de que tratarei aqui, diz respeito ao ato de conhecer uma proposição: este ato é simples ou composto?

'Primo sic: accipio cognitionem communem sive confusam quae correspondet isti voci 'homo' vel isti voci 'animal', et quaero aut aliquid intelligitur ista cogntione aut nihil" (Exp., I, 6, 34-36). 
"Em seguida, tomo o ato de conhecer uma proposição, e pergunto, o que é compreendido por tal ato? Ou algo simples, ou algo composto. 'Praeterea, accipio actum sciendi propositionem, et quaero quid intelligitur tali actu? Aut simplex aut compositum'" (Exp., I, 6, 64-65).

Não pode ser um ato simples, pois a proposição é composta pelo sujeito, pelo predicado e pela cópula. Se é um ato composto, de que é ele composto, i.e. do que é composta a proposição? A primeira hipótese, recusada, é que a proposição seja composta de coisas. A segunda hipótese vai oferecer a via ockhamiana de abordagem do problema. A proposição é composta de algo no intelecto, mas não de atos de intelecção. O modo como é apresentado o segundo membro da altemativa inicial é importante.

"Ou é composta de coisas no intelecto, e não a partir de atos de intelecção, pois senão além do ato de intelecção da proposição haveria outros atos a partir dos quais a proposição seria composta, e assim haveria muitos atos simultaneamente. Logo, alguma coisa outra que o ato de intelecção é compreendida, que também está no intelecto, e por conseguinte aquela outra coisa será mais verdadeiramente a paixão, da qual fala o Filósofo aqui, do que o ato de intelecção. 'Aut componitur ex aliquibus in intellectu, et non ex actibus intelligendi, quia tunc praeter actum intelligendi propositionem essent alii actus ex quibus componeretur propositio, et ita essent multi actus simul. Igitur aliquid aliud $\mathrm{ab}$ actu intelligendi intelligitur, quod tamen est in intellectu, et per consequens illud verius erit passio de qua Philosophus hic loquitur quam actus intelligendi'" (Exp., I, 6, 69-75).

Dado que (i) apreendemos uma proposição por um ato, (ii) é impossível haver diversos atos simultâneos no intelecto e (iii) toda proposição é composta, chega-se à conclusão que aquilo de que se compõe a proposição não pode ser um ato. Ora, a proposição é composta de termos - não há outros candidatos para desempenhar os papéis de sujeito, cópula e predicado - logo, termos não são atos do intelecto, chegamos portanto à recusa de tese defendida neste parágrafo. Se se diz que o ato de apreender de uma proposição é composto de diversos atos, chegamos também a uma dificuldade importante.

"E se se diz que o ato de apreender ou de conhecer uma única proposição não é um único ato simples, mas é um ato composto de muitos atos, os quais fazem todos uma única proposição; contra isto: então essas proposições, 'todo homem é animal' e 'todo animal é homem' não seriam distinguidas na mente. Com efeito, se essa proposição não for na mente senão ato de intelecção composto a partir dessas intelecções particulares, como não possa haver aqui numa única proposição algum ato particular que não exista na outra, e a diferença na ordem não impede [esta associação], como impede na linguagem falada, não se vê como possam ser distinguidas na mente. De maneira semelhante, $\mathrm{o}$ ato de conhecer distingue-se de todos aqueles atos tomados separada e simultaneamente, pois podem existir todos simultaneamente, embora não exista o ato de conhecer. 'Et si dicatur quod actus apprehendi sive sciendi unam propositionem non est aliquis unus actus simplex, sed est actus compositus ex multis actibus, qui omnes actus faciunt unam propositionem; contra hoc: tunc istae propositiones 'omnis homo est animal' et 'omne animal est homo' non distingueretur in mente. Nam si ista propositio in mente non sit nisi actus intelligendi compositus ex istis intellectionibus particularibus, cum non possit esse hic aliquis actus particularis in una propositione 
quin sit in alia, nec diversitas ordinis impedit sicut in voce impedit, non videtur quomodo possit distingui in mente. Similiter, actus sciendi distinguitur ab omnibus illis actibus divisim et simul sumptis, quia omnes possunt esse simul quamvis non sit actus sciendi"" (Exp., I, 6, 76-87).

Se se diz que proposições são compostas de diversos atos intelectivos, não há como fazer distinção entre 'todo homem é animal' e 'todo animal é homem'. Inicialmente, não há nenhum ato particular (sujeito, cópula, predicado) que esteja numa proposição que não esteja na outra, mas isto ocorre também com proposições faladas. O segundo problema é mais importante. Não é possível distinguir uma proposição da outra pela ordem, pois, pela hipótese examinada, os atos intelectivos são simultâneos, não havendo ordem temporal, não há nenhuma outra ordem disponível para distinguir as duas proposições.

Há mais uma resposta possível, diz Ockham. A primeira é que dizer que a proposição mental é um único composto de muitos atos de intelecção (propositio in mente est unum compositum ex multis actibus intelligendi, 111-112); a proposição 'homo est animal' é assim composta de um ato de intelecção de todos os homens, um ato de intelecção de todos os animais, e ato que corresponde à cópula. A segunda resposta acrescentada por Ockham é notável:

"Ou pode-se dizer que essa proposição é um único ato equivalente a tais três atos existindo simultaneamente no intelecto, e assim, segundo este modo de dizer, a proposição não é algo composto realmente, mas apenas por equivalência, isto é, é equivalente a tal composto. 'Vel potest dici quod ista propositio est unus actus aequivalens talibus tribus actibus simul exsistentibus in intellectu, et tunc secundum istum modum dicendi propositio non est aliquod compositum realiter sed tantum per aequivalentiam, hoc est, est aequivalens tali composito'" (Exp. I, 6, 115-119).

Deslocamento fundamental. Pode-se tanto dizer que a proposição é composta de tais atos quanto dizer que ela é um ato - falamos aqui da propositio in menteequivalente a tal composto. Ora, o que se diz aqui é que não é importante decidir de que modo se dá a realização psicológica de uma proposição, se ela é composta de diversos atos ou é apenas um ato. A vantagem conseguida com este movimento aparecerá contudo na passagem seguinte.

O problema que deve enfrentar Ockham é como diferenciar 'todo homem é animal' de 'todo animal é homem', ou, segundo o exemplo examinado abaixo, 'todo animal é branco' de 'todo branco é animal'. As duas sentenças devem ser diferenciadas pela ordem dos termos, mas não pode haver ordem temporal entre atos simultâneos, e não há outro parâmetro de ordenação disponivel para atos mentais.

"Em relação a isto pode-se dizer que a proposição pode ser o ato de intelecção equivalente a toda uma única proposição composta a partir de [coisas] realmente distintas, se tal ordem ocorresse tal como ocorre na linguagem falada. E assim serão proposições distintas segundo o modo como se distinguem proposições correspondentes se seus termos ou suas partes fossem ordenadas de maneiras diferentes. 'Ad istud potest dici quod propositio potest esse actus intellegendi aequivalens toti uni propositioni compositae ex realiter distinctis, si talem ordinem haberent qualem habent in voce. Et tunc erunt propositiones distinctae secundum quod distinguerentur propositiones correspondentes si termini earum seu partes aliter et aliter ordinarentur"' (Exp. I, 6, 129-133). 
Podemos apresentar o problema do seguinte modo:

a) as proposições 'todo animal é branco' e 'todo branco é animal' são diferentes;

b) esta diferença pode ser explicada ou por alguma diferença nos termos que as compõem, ou pela ordem destes termos;

c) não pode ser explicada por alguma diferença nos termos que as compõem, pois os termos são os mesmos, logo;

d) é explicada por uma diferença na ordem dos termos;

e) é preciso um critério para o reconhecimento da ordem dos termos;

f) este critério pode ser uma diferença espacial ou temporal;

g) em proposições faladas e escritas, a ordem é evidente;

h) em proposições mentais, não pode haver uma diferença espacial, logo deve haver alguma diferença temporal;

i) não pode haver diferença temporal pois, por hipótese, os atos que a compõem são simultâneos;

j) logo, deve-se dizer:

k) ou que as duas proposições mentais 'todo animal é branco' e 'todo branco é animal' são equivalentes, o que é absurdo;

1) ou que proposições mentais não são compostas, mas são atos simples, logo o problema da ordenação não se coloca, as duas proposições examinadas são simplesmente atos diferentes.

Os passos argumentativos de (a) a (d) são dificilmente contestáveis. A sentença (e) diz que é preciso um critério de distinção da ordem entre partes e, em relação às diversas linguagens, os critérios disponíveis são as distinções espacial e temporal (f). A alternativa seria dizer que há uma ordem intraproposicional identificada independentemente do reconhecimento de alguma ordenação espacial ou temporal; não há contudo candidatos para desempenhar tal papel, i.e. critérios altemativos para o reconhecimento de alguma ordenação lingüística. Se não há critérios para a identificação de ordem em trechos da linguagem, não há como se atribuir alguma ordem a tais trechos. A solução do problema vai girar em torno deste ponto. O restante do argumento vai dizer que como não temos tais critérios para a LM, logo devemos ou aceitar (k), que é absurdo, ou (l) - proposições mentais são atos simples, não compostos, não há portanto porque buscar um critério de identificação de ordens, não há tal ordem.

Esta não é contudo a solução ockhamiana. Com efeito, o Venerabilis Inceptor não diz que proposições mentais são simples, ao contrário, ele começa dizendo que proposições mentais são compostas de diversas atos. Como evitar então a situação paradoxal apontada em (k)? A solução ockhamiana aqui é dizer que proposições mentais devem ser equivalentes a proposições compostas, mas elas mesmas podem ser simples ou compostas. Resposta desconcertante, ao invés de dizer como proposições compostas podem escapar à conclusão $(\mathrm{k})$ ou que proposições mentais são atos simples, o filósofo inglês diz que proposições mentais devem ser equivalentes a proposições compostas, e a diferença entre 'todo animal é branco' e 'todo branco é animal' é que elas são equivalentes a proposições diferentes segundo a ordem das partes, se elas fossem compostas de partes realmente distintas e ordenadas. 
Ockham não procura aqui decidir o modo como proposições se realizam efetivamente na mente, não decide se apreendemos proposições por atos simples ou compostos, basta dizer que a organização dos termos determina o valor verdade de proposições, aqui, o termo sobre o qual incide a palavra 'todo', 'branco' ou 'animal'. Esta diferença é significativa, i.e. ela altera o valor verdade de proposições e, na medida em que é significativa, é um traço da LM. Sabemos que na LM, diferentemente das linguagens falada e escrita, tudo é significativo, não há nada na estrutura da LM que seja supérfluo à significação - ser significativo é portanto uma característica necessária às regras que constituem a LM. Aqui vemos que ser significativo é também um traço suficiente, se uma determinada regra é significativa na linguagem falada, ela pertence necessariamente à LM, e isto porque a linguagem falada é significativa precisamente por ser associada à LM.

Interessa a Ockham aqui a adoção do princípio de composicionalidade: o sentido do todo de uma frase é o sentido das partes e de sua combinação. Ora, a aplicação deste princípio não diz como a LM se compõe de fato, não diz como são os atos do nosso espírito, mas a que tais atos são equivalentes, na medida em que são significativos. É claro que não há nenhuma recusa da realidade psicológica da LM, todo o texto diz que proposições mentais são atos; não é necessário contudo encontrar o princípio de composicionalidade regulando a formação destes atos, ele só regula o modo como eles significam. Não se trata assim de desvendar a realização mental da linguagem a partir de uma análise semântica, não se trata de ler a estrutura lógica nas estruturas psicológicas, mas de saber como interpretar a LM.

Acredito que podemos ver a tarefa ockhamiana como interpretativa. O que é interpretação aqui? Interpretar é saber como proposições mentais significam pela associação a proposições equivalentes. A alternativa, na filosofia ockhamiana, seria a descoberta, pela análise semântica, de uma estrutura real que correspondesse a estas proposições equivalentes. Se a análise determinasse que uma característica $F$ (por exemplo, o princípio da composicionalidade) é significativa, deveríamos encontrar uma estrutura real à qual pudéssemos atribuir a característica $F$ (por exemplo, a composição de atos de que se compõem proposições mentais). Ora, vemos que Ockham não dá este passo e diz que basta saber a que expressão associar tal ou tal proposição mental, a que expressão tal proposição mental equivale. A formulação contrafactual, indicada pelo subjuntivo e pelo 'si' ("Et tunc erunt propositiones distinctae secundum quod distinguerentur propositiones correspondentes si termini earum seu partes aliter et aliter ordinarentur". Exp., I, 6, 131-133), marca justamente o caráter interpretativo.

Voltando à exposição do problema, a solução ockhamiana é dizer que se pode fazer duas perguntas em relação a proposições mentais: ou se pergunta como elas são formadas, ou como elas significam. Proposições mentais são formadas por atos intelectivos e não há critérios para determinar uma diferença de ordem entre tais atos, são atos simultâneos. A outra solução apontada por Ockham, de considerar atos intelectivos relativos a proposições como atos únicos não soluciona o problema, antes o dissolve, já que não há ordem com um só elemento. Mas deste ponto de vista, perde-se o ponto de partida do problema, a saber, a sentença (a), 'as 
proposições 'todo animal é branco' e 'todo branco é animal' são diferentes'. Consideradas deste ponto de vista, as duas proposições são diferentes porque são marcas escritas ou sinais sonoros com ordens diferentes, mas não há ligação entre o modo como sinais escritos ou sonoros se organizam e o modo como atos intelectivos são formados. Como não há ligação entre proposições escritas e mentais aqui, a sentença inicial (a) não diz mais respeito à LM, e não há problema nenhum a ser resolvido, a determinação da diferença entre as duas proposições escritas não se transfere para proposições mentais.

Se se pergunta contudo pelo que proposições significam, i.é. pelo seu valor de verdade, então a sentença (a) diz respeito tanto a proposições escritas e faladas quanto a proposições mentais. Deste ponto de vista contudo o critério para o reconhecimento da ordem da proposição deve ser revisto. Proposições têm condições de verdade diferentes em função das diferentes ordenações de suas partes; um critério para o reconhecimento da ordem entre os termos, (e) é um critério para identificação de diferentes condições de verdade para proposições. Para proposições faladas e escritas, é preciso um critério associado ao modo como proposições são formadas (f); para proposições mentais contudo não é preciso tal associação. Sabemos que proposições são diferentes porque damos assentimentos a elas em ocasiões diferentes, ou imaginamos diferentes situações nas quais daríamos assentimento a uma sentença a e não a uma outra sentença $b$, sem que seja necessário recorrer ao modo como elas são formadas na mente. Por esta razão a solução ockhamiana será dizer que proposições mentais relativas a 'todo animal é branco' e 'todo branco é animal' são diferentes porque são equivalentes a diferentes proposições, cuja diferença por sua vez pode ser explicada pela ordem entre os termos. Este contudo é um fato acerca das condições de verdade destas proposições, não acerca de sua realização no espírito. Pode-se retrucar dizendo que as diferentes condições de verdade são função de diferenças na ordem dos termos.

Uma resposta ockhamiana poderia ser dada em dois tempos. Inicialmente, pode-se dizer que diferentes proposições mentais são equivalentes a diferentes proposições cujas condições de verdade podem ser descritas como funções de suas partes. Em seguida, acredito, o filósofo inglês poderia dizer que saberíamos a que proposição associar tal proposição mental porque saberíamos quando dar ou não nosso assentimento a tal ou tal proposição: se damos nosso assentimento a duas proposições nas mesmas condições, reais ou contrafactuais, então são a mesma proposição. Esta formulação talvez fique um pouco obscura sem a distinção entre sentença e proposição, entre type e token, ausente da filosofia ockhamiana; aqui certamente é um caso de considerar sentenças, não proposições, mas isto não altera nosso argumento geral. Esta resposta talvez tenha um aspecto um pouco anacrônico, mas uma outra resposta mais ockhamiana que consigo imaginar seria ainda mais direta: qualquer pessoa que compreenda 'todo animal é branco' e 'todo branco é animal' sabe que significam coisas diferentes, e saberá portanto que proposições mentais diferentes são equivalentes a cada uma delas. Cada falante é capaz de compreender uma sentença realizada na sua mente e isto significa que entre as duas sentenças 'todo animal é branco' e ‘todo branco é animal', 
ele saberá a qual delas associar sua sentença mental, e isto qualquer que seja a realização mental desta sentença, i.é. seja ela composta ou não. Por isto Ockham pode simplesmente dizer que a proposição mental pode ser simples ou composta e que sabemos a que sentença falada ou escrita uma dada sentença mental é equivalente, portanto sabemos identificar diferenças entre sentenças. Para isto não é preciso mais do que nossa intuição lingüística.

\section{III}

A semântica como interpretação, por um lado, e a idéia de uma linguagem mental, por outro, são temas recorrentes na filosofia contemporânea, embora não ligados. A associação com temas de filósofos contemporâneos pode ajudar a esclarecer minha leitura de Ockham.

Inicialmente, a idéia de uma semântica interpretativa, tal como caracterizada por Gareth Evans:

"O semanticista interpretacional procura caracterizar a noção de uma interpretação admissível para uma linguagem, ou para um fragmento de uma linguagem, considerado como feito de expressões de certas categorias semânticas definidas; expressões da mesma categoria recebem, sob qualquer interpretação admissível, uma atribuição do mesmo tipo" (Evans, 33).

Este tipo de semântica opõe-se à teoria dos modelos: não se trata de achar uma estrutura fixa à qual se deveria associar expressões lingüísticas, e em seguida determinar o modo como expressões lingüísticas significam por sua relação com esta estrutura fixa, seja ela real ou teórica. Se entendo o que Evans pretende aqui, trata-se de achar critérios de significação para todas as expressões, critérios que permitem a formação de categorias de expressões equivalentes, mas que não criam um domínio privilegiado, por exemplo, com uma interpretação fixa, a compreensão de outras expressões dependendo da associação a este domínio canônico. Não esquecendo a enorme distância que separa estes dois filósofos ingleses, o que há de comum é a recusa da constituição de um domínio lingüístico canônico em relação a outros domínios constituído pela aplicação de critérios semânticos, seja este domínio real (a LM ockhamiana) ou teórico (como um modelo construído dentro de uma teoria semântica); o que se ganha com a aplicação de tais critérios é uma classe de expressões equivalentes.

Voltando a Ockham, o que este paralelo permite esclarecer é que a aplicação de critérios semânticos para a identificação de estruturas significativas forma uma classe de expressões equivalentes, nas quais as proposições da LM não têm qualquer privilégio. Deste ponto de vista, as linguagens mental, falada e escrita são equivalentes, significam do mesmo modo; mesmo que a gênese do caráter significativo de cada uma destas linguagens não seja a mesma, o que é significativo em cada uma delas é igual, as regras de constituição de expressões significativas são as mesmas. E não poderia ser diferente, já que não temos acesso ao que é significativo na LM senão pela análise das linguagens falada e escrita. 
Outra associação pode ser feita com um texto de Stephen Schiffer, "A Paradox of Meaning". Schiffer examina justamente a composicionalidade da linguagem mental (Mentalês ou lingua mentis). O que ele propõe está notavelmente próximo do Ockham que vimos aqui. Não é necessário supor que a linguagem mental tenha uma estrutura composicional, o que não implica negar a estrutura composicional das línguas naturais (linguagens falada e escrita para Ockham). Línguas naturais podem ter uma semântica composicional e ser associadas a representações mentais que por sua vez não têm uma semântica composicional. Como isto é possível? Basta, diz Schiffer, uma teoria da superveniência composicional (compositional supervenience theory):

"Esta teoria oferece um modo finito de relacionar cada sentença do mentalês com a propriedade física sobre a qual seu sentido sobrevém (supervenit), mas não faz nada para explicar porque um dado sentido deve sobrevir à propriedade física que é sua base de superveniência" [Schiffer, 316].

É possível assim tratar o correspondente mental de sentenças de línguas naturais como não tendo uma semântica composicional, embora tenha uma teoria da superveniência composicional. A teoria da superveniência não é uma teoria do sentido porque os itens com os quais trabalha não são determináveis dentro de uma semântica composicional, não há uma ligação sistemática entre realizações físicas e valores semânticos que pudesse fornecer o material de construção de uma semântica composicional. Isto significa que não vamos encontrar uma realização física para a descrição do modo como a organização de partes de sentenças determina seu valor semântico - um equivalente físico para palavras, por exemplo. Basta uma teoria semântica capaz de descrever de maneira sistemática a composicionalidade de sentenças numa língua natural qualquer, independente de sua realização neural. Uma teoria para o mentalês, por sua vez, dará uma descrição sistemática, composicional da realização física de sentenças, cujas partes não têm um valor semântico. A passagem entre uma teoria e outra será uma teoria do uso da lingua mentis de cada falante, a associação para cada falante entre um determinado estado neural e uma sentença da linguagem pública. Esta associação contudo não deve necessariamente ser descrita por uma teoria composicional (Schiffer, 298).

Esta posição está notavelmente próxima de Ockham: não é preciso achar uma realização mental para a composição semântica de sentenças, basta poder ver como sentenças significam, como são equivalentes a tal ou tal expressão com uma semântica composicional. Não é preciso descrever uma realização composicional para sentenças mentais, basta saber como associar uma dada sentença mental a uma sentença cujo sentido possa ser determinado de maneira composicional.

Mais uma vez, uma grande distância separa os dois filósofos, mas acredito que ganhamos algo na compreensão da leitura proposta. Inicialmente, a independência entre realização física e teoria semântica pode ser feita em Schiffer pela não determinação semântica da sistematicidade das realizações neurais da lingua mentis, isto é, as partes de uma determinada realização neuronal de sentenças 
não são partes semanticamente determináveis. Esta independência não pode ocorrer em Ockham, já que a descrição de partes de que se compõem sentenças recorre a atos intelectivos, potencialmente determináveis dentro de uma teoria semântica: o conhecimento de Sócrates pode tornar-se ou antes é um signo de Sócrates. ${ }^{2}$ Este paralelo mostra contudo que as razões pelas quais devemos ter uma teoria semântica composicional não aparecem numa teoria para a realização mental de cada sentença, a associação entre um estado da mente e uma sentença não é uma teoria para sentenças, mas uma outra teoria, uma teoria do conhecimento, para Ockham, e uma teoria da mente, para Schiffer. Interessante observar que as razões de um e de outro autor para uma semântica composicional não são exatamente as mesmas. E esta saída é possível pela consideração da dimensão interpretativa ou de tradução (Schiffer, 310) de uma teoria semântica.

"Estes paralelos pretendem esclarecer um ponto filosófico, mas devo ressaltar que 0 interesse central de minha comunicação é esclarecer uma passagem do texto ockhamiano, a saber, o aparente paradoxo da recusa do principio de composicionalidade para a LM. A distinção entre dois tipos de funcionamento do recurso à LM e a caracterização de um destes recursos como interpretativo ajudam a compreender a passagem em questão e, de maneira mais geral, outros pontos da filosofia da linguagem ockhamiana."

\section{Referências bibliográficas}

EVANS, Gareth. The Varieties of Reference. Oxford: Clarendon, 1982.

OCKHAM, Guillermi de. Expositio in Librum Perihermenias Aristotelis. Ed. G. GÁL. Opera Philosophica

II. St. Bonaventure: St. Bonaventure University, 1978. [Exp. Per.]

PANACCIO, Claude. Intuition, Abstraction et Langage Mental dans la théorie occamiste de la Connais-

sance. Revue de Métaphysique et de Morale. n. 1. p. 61-81, 1992.

SCHFFER, Stephen. A Paradox of Meaning. Noûs. 28:3. p. 279-324, 1994.

2 Uma comparação interessante poderia ser feita aqui mais uma vez com Evans: "It seems to me that there must be a sense in which thoughts are structured. [...]. However, I certainly do not wish to be committed to the idea that having thoughts involves the subject's using, manipulating, or apprehending symbols - which would be entities with non semantic as well as semantic properties, so that the idea I am trying to explain would amount to the idea that different episodes of thinking can involve the same symbols, identified by their semantic and non semantic properties. I should prefer to explain the sense in which thoughts are structured, not in terms of their being composed of several distinct elements, but in terms of their being a complex of the exercice of several distinct conceptual abilities" (Evans, 100-101). 